\title{
GAMBARAN IMPLEMENTASI PROGRAM RUJUK BALIK (PRB) BPJS KESEHATAN DI PUSKESMAS WILAYAH KERJA KECAMATAN TANAH SAREAL KOTA BOGOR TAHUN 2018
}

\author{
Fajar Rinata $^{1)}$, Asri Masitha Arsyati ${ }^{2)}$, Husnah Maryati ${ }^{3)}$
}

\author{
${ }^{1)}$ Konsentrasi Manajemen Pelayanan Kesehatan,Program Studi Kesehatan Masyarakat, FIKES UIKA Bogor \\ Email : fajarrinnata@gmail.com \\ ${ }^{2}$ Program studi Kesehatan Masyarakat Fakultas Ilmu Kesehatan Universitas Ibn Khaldun Bogor \\ Email : asri.masitha@gmail.com \\ ${ }^{3)}$ Rumah Sakit Umum Daerah Kota Bogor,Jl.Dr.Semeru no.120 Telp (0251) 8312292 Fax: 8371001,Bogor 16111 Jawa \\ Barat. \\ Email : anatanzili@gmail.com
}

\begin{abstract}
Abstrak
Puskesmas sebagai fasilitator rujukan pasien, seringkali menerima rujukan balik pasien dari rumah sakit, namun tidak semua puskesmas melaksanakan program rujuk balik dengan baik. Tujuan penelitian ini adalah untuk mengetahui gambaran pelaksanaan Program Rujuk Balik (PRB) di puskesmas meliputi penilaian beberapa aspek yang berperan dalam kelangsungan program rujuk balik diantaranya terdiri dari pengetahuan, pelayanan obat rujuk balik, struktur birokrasi, disposisi, komunikasi dan sumber daya.Penelitian ini menggunakan metode penelitian deskriptif dengan uji analisis univariat pada masing-masing variabel yang diteliti melalui kuesioner sebagai instrumen penelitian. Sampel dalam penelitian ini berjumlah 20 responden petugas pelaksana program rujuk balik di Puskesmas Wilayah Kerja Kecamatan Tanah Sareal Bogor. Penentuan sampel menggunakan metode nonprobability sampling dengan teknik pengambilan sampel secara purposive sampling. Hasil penelitian diperoleh persentase gambaran pelaksanaan Program Rujuk Balik (PRB) di Puskesmas Wilayah Kerja Kecamatan Tanah Sareal Bogor dalam aspek pengetahuan (80\%), pelayanan obat PRB (80\%), disposisi (65\%), dan sumber daya (70\%) sudah berjalan baik, sementara dalam aspek struktur birokrasi (50\%) dan komunikasi (55\%) belum berjalan baik dan perlu di kembangkan. Dalam pelaksanaan PRB di Puskesmas Wilayah Kerja Kecamatan Tanah Sareal Bogor sudah cukup berjalan baik, namun diharapkan perlu dikembangkan upaya kordinasi dan komunikasi lebih baik lagi antara instansi terkait guna kelangsungan program berjalan lebih baik.
\end{abstract}

\section{Kata Kunci : Implementasi, Rujuk Balik, Puskesmas}

\section{PENDAHULUAN}

WHO (2012) menyatakan bahwa dari 52 juta kematian global pada tahun 2008, sebesar 36 juta atau sekitar $63 \%$ disebabkan oleh penyakit tidak menular. Empat penyakit tidak menular yang utama yaitu Jantung, Kanker, Diabetes dan penyakit Paru Kronik.
WHO (2017) pun menyatakan bahwa terdapat beberapa penyakit kronis yang termasuk ke dalam kategori penyakit tidak menular menyumbangkan angka kematian terbesar yaitu 17,5 juta jiwa pada penyakit kardiovaskular, 8,8 juta jiwa angka kematian 
pada penyakit kanker, 3,9 juta jiwa kematian pada penyakit pernafasan kronis dan kematian pada penyakit diabetes militus sebesar 1,6 juta jiwa.

Di Indonesia, penyakit kronis pada era JKN dapat ditangani dengan program rujuk balik (PRB) yang merupakan program BPJS kesehatan dalam menjamin kebutuhan obat untuk pasien-pasien yang menderita penyakit kronis. Rujuk Balik berlaku untuk penyakit kronis yang sudah dinyatakan stabil oleh dokter spesialis rumah sakit ke FKTP. Namun, pada pelaksanannya selalu tidak sesuai dengan keadaan yaitu tidak tanggapnya pasien terhadap program rujuk balik, demikian pula petugas kesehatan di dalam melayani pasien kronis (Noverdita 2017).

\section{METODE}

Penelitian ini merupakan penelitian deskriptif dengan pendekatan kuantitatif. Instrumen penelitian berupa kuesioner yang dibagikan kepada 20 responden secara purposive sampling yaitu petugas puskesmas yg terlibat dalam PRB di Puskesmas Wilayah Kerja Kecamatan Tanah Sareal Bogor.
Penelitian yang dilakukan oleh Primasari (2015) mengemukakan bahwa ada beberapa faktor yang berperan penting dalam keterlaksanaan Program Rujuk Balik (PRB) yaitu : Pengetahuan dokter tentang Program Rujuk Balik (PRB), ketersediaan obat di fasilitas layanan pertama, informasi dan komuniaksi yang akurat dan lengkap dari BPJS Kesehatan mengenai Program Rujuk Balik (PRB). Menurut Rakhmawati dalam penelitian yang dilakukan di RSUD Kota Depok Tahun 2016, ditemukan bahwa implementasi program rujuk balik di RSUD Kota Depok belum efektif. Masih terdapat banyak kekurangan dari segi ketersediaan obat rujuk balik, sumber daya, komunikasi antar organisasi, dan disposisi implementor (Caesaria, 2016).

Dalam penelitian ini digunakan analasis univariat untuk mengetahui persentase dari masing-masing variabel yang mempengaruhi implementasi program rujuk balik (PRB) di Puskesmas mengacu pada teori Sugiyono (2008).

\section{HASIL}

\section{Pengetahuan}

Tabel 1. Hasil Analisis Univariat Pengetahuan

\begin{tabular}{ccc}
\hline Skor & Frekuensi & Persen \\
\hline 80 & 4 & 20.0 \\
100 & 16 & 80.0 \\
\hline Total & 20 & 100.0 \\
\hline
\end{tabular}

Pada Variabel Pengetahuan, terdapat skor maksimal yaitu (100) bila responden menjawab seluruh item pertanyaan dengan benar. Diketahui sebanyak 16 responden menunjukan ketepatan jawaban dengan persentase $(80 \%)$ hal ini menunjukan bahwa implementasi pengetahuan responden tentang pelayanan PRB di puskesmas sudah berjalan dengan baik. 


\section{Pelayanan Obat}

Tabel 2. Hasil Analisis Univariat Pelayanan Obat

\begin{tabular}{ccc}
\hline Skor & Frekuensi & Persen \\
\hline 75 & 4 & 20 \\
100 & 16 & 80 \\
\hline Total & 20 & 100 \\
\hline
\end{tabular}

Pada Variabel Pelayanan obat, terdapat skor maksimal yaitu (100) apabila responden menjawab seluruh item pertanyaan dengan benar. Diketahui sebanyak 16 responden menunjukan ketepatan jawaban dengan persentase $(80 \%)$ hal ini menunjukan bahwa implementasi pelayanan obat PRB di puskesmas wilayah kerja kecamatan tanah sareal sudah berjalan dengan baik.

\section{Struktur Birokrasi}

Tabel 3. Hasil Analisis Univariat Struktur Birokrasi

\begin{tabular}{ccc}
\hline Skor & Frekuensi & Persen \\
\hline 80 & 10 & 50 \\
100 & 10 & 50 \\
\hline Total & 20 & 100 \\
\hline
\end{tabular}

Pada Variabel Struktur Birokrasi, terdapat skor maksimal yaitu (100) apabila responden menjawab seluruh item pertanyaan dengan benar. Diketahui hanya sebanyak 10 responden menunjukan ketepatan jawaban dengan persentase (50\%) hal ini menunjukan bahwa implementasi struktur birokrasi dalam PRB di puskesmas wilayah kerja kecamatan tanah sareal belum berjalan secara efektif.

\section{Disposisi}

Tabel 4. Hasil Analisis Univariat Disposisi

\begin{tabular}{ccc}
\hline Skor & Frekuensi & Persen \\
\hline$\leq 80$ & 7 & 35 \\
100 & 13 & 65 \\
\hline Total & 20 & 100 \\
\hline
\end{tabular}

Pada Variabel Disposisi, terdapat skor maksimal yaitu (100) apabila responden menjawab seluruh item pertanyaan dengan benar. Diketahui sebanyak 13 responden menunjukan ketepatan jawaban dengan persentase (65\%) hal ini menunjukan disposisi dalam implementasi PRB di puskesmas wilayah kerja kecamatan tanah sareal sudah berjalan baik. 


\section{Komunikasi}

Tabel 5. Hasil Analisis Univariat Komunikasi

\begin{tabular}{ccc}
\hline Skor & Frekuensi & Persen \\
\hline$\leq 60$ & 4 & 20 \\
80 & 5 & 25 \\
100 & 11 & 55 \\
\hline Total & 20 & 100 \\
\hline
\end{tabular}

Pada Variabel Komunikasi, terdapat skor maksimal yaitu (100) apabila responden menjawab seluruh item pertanyaan dengan benar. Diketahui hanya sebanyak 11 responden menunjukan ketepatan jawaban dengan persentase $(55 \%)$ hal ini menunjukan bahwa implementasi dalam aspek komunikasi terkait PRB di puskesmas wilayah kerja kecamatan tanah sareal belum berjalan secara efektif.

\section{Sumber Daya}

Tabel 6. Hasil Analisis Univariat Sumber Daya

\begin{tabular}{ccc}
\hline Skor & Frekuensi & Persen \\
\hline$\leq 70$ & 4 & 20 \\
83 & 2 & 10 \\
100 & 14 & 70 \\
\hline Total & 20 & 100 \\
\hline
\end{tabular}

Pada Variabel Sumber Daya, terdapat skor maksimal yaitu (100) artinya responden menjawab seluruh pertanyaan dengan benar. Diketahui sebanyak 14 responden menunjukan ketepatan jawaban dengan

\section{PEMBAHASAN}

Gambaran Pengetahuan responden petugas PRB di PKM Kecamatan Tanah Sareal dinilai sudah baik (80\%), hal ini berbeda pada hasil penelitian oleh Ali, dkk (2016) yang menyatakan bahwa pemahaman petugas di PKM Kalumata, Ternate tentang kebijakan PRB tergolong kurang baik. oleh karena itu perlu kegiatan pendukung bagi beberapa responden yakni petugas pelaksana rujukan di puskesmas agar mendapatkan penambahan ilmu berdasarkan bidang pelayanan rujukan, seperti kegiatan magang petugas puskesmas ke rumah sakit, pelatihan petugas pelayanan rawat jalan dan persentase $(70 \%)$ hal ini menunjukan bahwa implementasi sumber daya dalam pelayanan PRB di puskesmas wilayah kerja kecamatan tanah sareal sudah berjalan secara baik.

sebagainya guna menumbuhkan kualitas SDM yang lebih baik lagi dalam aspek pengetahuan petugas di Puskesmas. Menurut Kusumawati (2016) hal yang dapat dilakukan untuk menambah kemampuan petugas PKM adalah berupa magang / pelatihan di RSU yang lebih lengkap untuk melatih daya tangkap dan kompetensi petugas dalam pelayanan rujukan.

Sistem pelayanan obat PRB di Wilayah Kerja Kecamatan Tanah Sareal sudah berjalan baik (80\%), PKM Kec Tansa berperan sebagai penapis rujukan obat peserta PRB ke apotek jejaring BPJS 
Kesehatan. Hal ini sejalan dengan Sihombing (2017) bahwa ketersediaan obat PRB tidak selalu tersedia di Puskesmas, pasien di rujuk ke apotek jejaring dengan masa waktu 3 kali tebus obat selama 3 bulan. Ketersediaan obat PRB tidak selalu tersedia di Puskesmas, oleh karena itu Puskesmas akan membantu pasien PRB untuk menebus obat di apotek PRB jejaring BPJS Kesehatan. Menurut UU No. 36 Tahun 2009 tentang kesehatan pasal 36 ayat1, bahwa pemerintah menjamin ketersediaan, pemerataan dan keterjangkauan perbekalan kesehatan terutama obat esensial.

Sesuai dengan panduan program rujuk balik bahwa obat PRB diberikan untuk kebutuhan maksimal 30 hari setiap kali peresepan dan harus sesuai dengan daftar obat formularium nasional. Pelayanan obat rujuk balik adalah pemberian obat - obatan untuk penyakit kronis di fasilitas kesehatan tingkat pertama berdasarkan resep dokter spesialis di rumah sakit. (BPJS, 2014).

Implementasi PRB di Puskesmas Wiayah Kerja Kecamatan Tanah Sareal Bogor dalam struktur birokrasi dinilai masih kurang (50\%) salah satunya dalam hal kordinasi dan penerapan SOP khusus PRB. Begitupun dalam Permatasari (2017) menjelaskan bahwa dalam pelaksanaannya di FKTP (Puskesmas) wilayah kerja BPJS Kesehatan Cabang Utama Jakarta Selatan didapatkan belum adanya Standar Operasional Prosedur (SOP) untuk menjalankan PRB. FKTP hanya berperan dalam menjalankan program tersebut sesuai dengan arahan yang diberikan oleh BPJS Kesehatan. Sedangkan kordinasi yang dilakukan oleh FKTP hanya sebatas kordinasi kepada pihak BPJS Kesehatan sebagai penyelenggara jaminan kesehatan. Selain itu, tidak terdapat struktur organisasi khusus untuk menjalankan program rujuk balik pada FKTP.
Gambaran Disposisi dalam kelangsungan PRB di Puskesmas terkait sikap pelaksana program dalam wewenang, serta pelaksanaan kebijakan PRB dalam pemenuhan administrasi pasien, sudah berjalan baik $(65 \%)$, hasil tersebut sesuai dengan Permatasari (2017) dalam penelitiannya mengatakan bahwa Disposisi adalah faktor keberhasilan program rujuk balik, dilihat dari sikap pelaksana program dan pemenuhan kebijakan program.

Dalam implementasi suatu kebijakan perlu sekali reward kepada petugas pelaksana oleh pimpinan, salah satu bentuk penghargaan adalah diadakannya insentif kerja bagi petugas. Insentif kerja berguna dalam menambah motivasi kerja petugas, namun demikian dalam implementasi PRB berdasarkan hasil menunjukan bahwa petugas pelaksana pelayanan PRB di Puskesmas Wilayah Kerja Kecamatan Tanah Sareal tidak mendapatkan uang insentif, karena kegiatan pelayanan PRB tidaklah khusus dan memang sudah biasa dilakukan.

Penjelasan tersebut sesuai dengan penelitian Permatasari (2017) dalam penelitian tersebut juga menyebutkan bahwa berdasarkan informasi yang didapatkan, tidak ada insentif khusus yang diberikan untuk menjalankan program rujuk balik. Hal tersebut dikarenakan PRB merupakan tugas wajib yang harus dilaksanakan oleh petugas. Insentif hanya diberikan apabila petugas melakukan kerja lembur diluar jam kerja dan diluar tugasnya.

Kelangsungan komunikasi dalam pelayanan PRB di Puskesmas Kecamatan Tanah Sareal belum berjalan secara efektif (55\%). Proses penyampaian informasi PRB tidak rutin di sosialisasikan, hanya pada saat pembaharuan saja. Hal tersebut sejalan dengan Sihombing (2017) minat pasien PTM untuk mengikuti PRB tergolong rendah karena kurangnya komunikasi dan kordinasi 
PKM kepada dokter RS. Begitupun dalam Primasari (2015),kurangnya informasi dari BPJS Kesehatan kepada dokter tentang rujuk balik menyebabkan perbedaan persepsi antara petugas kesehatan di PKM dengan pasien sehingga PRB tidak berjalan optimal. Kurangnya perhatian pemerintah terhadap PRB juga menyebabkan penyebaran informasi tidak berjalan efektif (Luti, dkk 2012).

Ketersediaan sumber daya dalam kelangsungan PRB di Puskesmas Wilayah

\section{PENUTUP}

Implementasi Program Rujuk Balik (PRB) dalam pengetahuan Petugas Pelaksana Pelayanan PRB di Puskesmas Wilayah Kerja Kecamatan Tanah Sareal yaitu Mekarwangi, Tanah Sareal, Kedung Badak, Kayu Manis, didapatkan $(80 \%)$ gambaran pengetahuan petugas pelaksana dalam implementasi PRB di Puskesmas sudah baik, dan (80\%) Implementasi PRB dalam pelayanan obat di puskesmas sudah berjalan baik dengan membantu melayani pasien PRB ke apotek jejraing BPJS Kesehatan untuk melakukan penebusan resep obat. Sedangkan Implementasi PRB dalam aspek Struktur Birokrasi $(50 \%)$ belum terlaksana secara efektif. (65\%) gambaran disposisi dalam implementasi PRB di puskesmas sudah berjalan dengan baik sedangkan (55\%)
Kerja Kecamatan Tanah Sareal keseluruhan sudah berjalan baik (70\%). Salah satu sumber daya dalam kelangsungan PRB adalah pemenuhan ketersediaan obat generik dan obat PRB di Puskesmas. Sumber dana PRB berasal dari dana kapitasi BPJS Kesehatan. Hal tersebut sesuai dengan penelitian oleh Permatasari (2017) bahwa tidak ada sumber pendanaan khusus dalam PRB di Puskesmas melainkan hanya di dapat melalui dana kapitasi BPJS Kesehatan.

implementasi penyampaian informasi serta sosialisasi PRB di puskesmas dengan instansi kesehatan luar, seperti Dinas kesehatan dan Rumah Sakit masih belum efektif hanya sebatas menerima dan melayani.

Disarankan bagi pihak Puskesmas Wilyah Kerja Kecamatan Tanah Sareal Bogor untuk melakukan kordinasi yang kuat antar instansi seperti Dinas Kesehatan, BPJS dan Rumah sakit dalam pelayanan PRB secara konsisten dan terbuka. Puskesmas perlu membentuk organisasi khusus atau tim khusus dalam pelayanan PRB. Selain itu puskesmas perlu membuat Standard Operational Procedure (SOP) khusus PRB di unit pelayanan rawat jalan agar implementasi PRB lebih optimal dan sesuai yang diharapkan. 


\section{DAFTAR PUSTAKA}

[1] Ali, Fauziah Abdullah. dkk. (2015). Analisis Pelaksanaan Rujukan Rawat Jalan Tingkat Pertama Peserta Program Jaminan Kesehatan Nasional (JKN) Di Puskesmas Siko Dan Puskesmas Kalumata Kota Ternate Tahun 2014.JIKMU.Volume. 5 Nomor 2. UNSRAT

[2] BPJS Kesehatan. (2014). Panduan Praktis Program Rujuk Balik Bagi Peserta JKN. Jakarta: BPJS Kesehatan

[3] Caesaria. R. (2016). Efektifitas Implementasi Program Rujuk Balik Peserta Jaminan Kesehatan Nasional di Rumah Sakit Umum Daerah (RSUD) di Kota Depok Tahun 2016. Depok. Fakultas Kesehatan Masyarakat. Universitas Indonesia.

[4] Kusumawati, Nur Indah. (2016). Faktor-Faktor yang Mempengaruhi Pelaksanaan Program Rujuk Balik (PRB) Pasien Penderita Penyakit Kronis Peserta BPJS Kesehatan di Daerah Istimewa Yogyakarta (DIY). Fakultas Kedokteran Ilmu Kesehatan Masyarakat, UGM, Yogyakarta.

[5] Luti, Hasanbasri, Lazuardi. (2012). Kebijakan Pemerintah Daerah Dalam Meningkatkan Sistem Rujukan Kesehatan Daerah Kepulauan di Kabupaten Lingga Provinsi Kepulauan Riau. Fakultas Kedokteran Ilmu Kesehatan Masyarakat, UGM, Yogyakarta.

[6] Noveradita, Tri. (2017). Faktor-faktor Yang Berhubungan Dengan Kesertaan Program Pengelolaan Penyakit Kronis (PROLANIS) Pada Peserta Program
Rujuk Balik di Kota Depo. Depok: Fakultas Kesehatan Masyarakat. Universitas Indonesia

[7] Permatasari, A. S. (2017). Implementasi Pelaksanaan Program Rujuk Balik (PRB) di Wilayah Kerja BPJS Kesehatan Kantor Cabang Utama Jakarta Selatan Tahun 2017. Depok: Fakultas Kesehatan Masyarakat. Universitas Indonesia

[8] Primasari, K.L. (2015). Analisis Sistem Rujukan Jaminan Kesehatan Nasional RSUD. Dr. Adjidarmo Kabupaten Lebak. Jurnal Administrasi Rumah Sakit Indonesia. Volume 1 No 2. ISSN : 2406-9108.

[9] Sihombing, Ita N.S. (2018). Analisis Pelaksanaan Program Rujuk Balik (Studi Kasus Pelaksanaan Program Rujuk Balik Pada Program Jaminan Kesehatan Nasional di Puskesmas Pancur Batu Kabupaten Deli Serdang Tahun 2017. Universitas Sumatera Utara.

[10] Sugiyono. (2008). Metode Kuantitatif Kualitatif dan $R \& D$. Bandung : ALFABETA

[11] World Health Organization. (2012). Death from NCDs.http://www.who.int/gho/ncd/mor tality_mobidity/ncd_total_text/en/index . Html diakses pada Agustus 2018.

[12] World Health Organization. (2017). Cardiovascular diseases (CVDs). http://who.int/mediacentre/factsheets/fs 317/en/. Html diakses pada Agustus 2018. 